\title{
Asymmetric Choreography in Pairs of Orthogonal Rotors
}

Antonio Rodríguez-Fortea, ${ }^{\dagger}$ ] Jiří Kaleta, ${ }^{\ddagger}$ Cécile Mézière, ${ }^{\S}$ Magali Allain, ${ }^{\S}$ Enric Canadell,*,\|] Pawel Wzietek, ${ }^{*, \perp}$ Josef Michl, ${ }^{*,+, \#}$ and Patrick Batail ${ }^{*, \$(}$

${ }^{\dagger}$ Departament de Química Física i Inorgànica, Universitat Rovira i Virgili, Marcel·lí Domingo 1, 43007 Tarragona, Spain

${ }^{\ddagger}$ Institute of Organic Chemistry and Biochemistry, Academy of Sciences of the Czech Republic, Flemingovo nam, 2, Prague 6, 16610 Prague, Czech Republic

${ }^{\S}$ Laboratoire MOLTECH-Anjou, CNRS UMR 6200, Université d'Angers, 49045 Angers, France

"Institut de Ciència de Materials de Barcelona (ICMAB-CSIC), Campus de la UAB, 08193 Bellaterra, Spain

${ }^{\perp}$ Laboratoire de Physique des Solides, CNRS \& Université de Paris-Sud, 91405 Orsay, France

\# Department of Chemistry and Biochemistry, University of Colorado Boulder, Boulder, Colorado 80309-0215, United States

Supporting Information
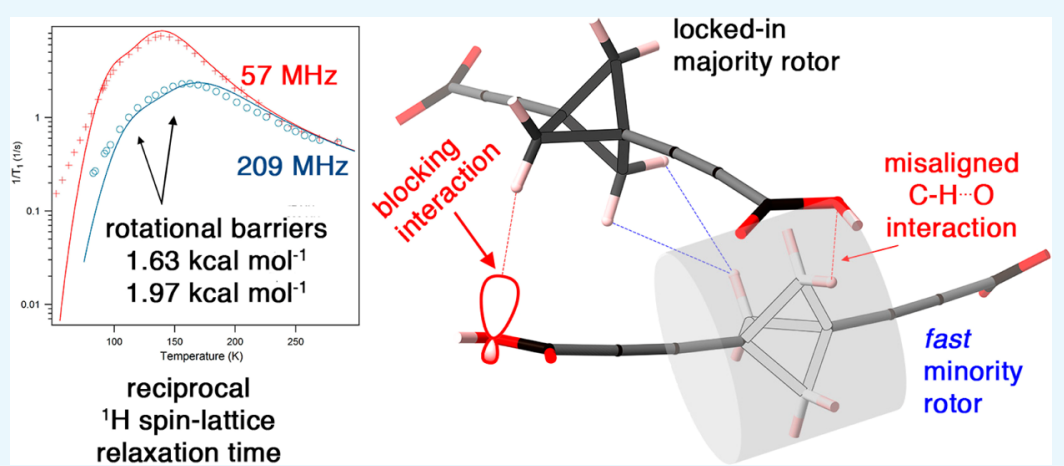

ABSTRACT: An asymmetric mechanism for correlated motion occurring in noninteracting pairs of adjacent orthogonal 1,4bis(carboxyethynyl)bicyclo[1.1.1]pentane (BCP) rotators 1 in the solid state is unraveled and shown to play an important role in understanding the dynamics in the crystalline rotor, $\mathrm{Bu}_{4} \mathrm{~N}^{+}\left[\mathbf{1}^{-}\right] \cdot \mathrm{H}_{2} \mathrm{O}$. Single crystal X-ray diffraction and calculation of rotorrotor interaction energies combined with variable-temperature, variable-field ${ }^{1} \mathrm{H}$ spin-lattice relaxation experiments led to the identification and microscopic rationalization of two distinct relaxation processes.

\section{INTRODUCTION}

A recent investigation of a hybrid system of molecular conductors and molecular rotors based on 1,4-bis(carboxyethynyl)bicyclo[2.2.2] octane (BCO) rotators 2 (Scheme 1) identified the phenomenon of quantum dissipation as a possible channel for severely impeding the rotational motion in the metallic state above the metal-insulator transition where the carriers become localized. ${ }^{1}$ Extending this nascent class of materials to 1,4-bis(carboxyethynyl)bicyclo[1.1.1] pentane (BCP) rotators ${ }^{2} 1$ requires the synthesis (Supporting Information) of $\mathrm{Bu}_{4} \mathrm{~N}^{+}\left[\mathbf{1}^{-}\right] \cdot \mathrm{H}_{2} \mathrm{O}$ from its parent biscarboxylic acid for this counter-anion to be engaged as an electrolyte in electrocrystallization experiments with $\pi$-conjugated electron donors. Here, we analyze the $\mathrm{X}$-ray structure and dynamics of $\mathrm{Bu}_{4} \mathrm{~N}^{+}\left[\mathbf{1}^{-}\right] \cdot \mathrm{H}_{2} \mathrm{O}$ by means of variabletemperature variable-field ${ }^{1} \mathrm{H}$ spin-lattice relaxation experiments coupled to rotor-rotor interaction energy calculations. In the course of this work, we discovered a new mechanism for correlated motion $^{3-5}$ in a pair akin to a choreography performed by a duo of ballet dancers who take turns to be similar to the more static solid anchor, supporting an agile, faster-moving, less-constrained partner. We thereby provide a valuable insight ${ }^{6}$ into an asymmetric motion of geared molecular units whose axles are orthogonal, that is, offset in a way that makes such an unexpected choreography nonintuitive. For example, once the mechanism of correlated motion in strongly coupled pairs of parallel BCO rotators was deciphered in $3{ }^{4}$ the proper synchronous gear-like motion, as well as the occasional asynchronous gear-slippage, seemed intuitive enough; likewise for the correlated motion in the pairs of significantly more weakly coupled parallel BCP rotators in 4 . $^{5}$

\section{RESULTS AND DISCUSSION}

One Single Site: Two Equilibrium Positions. The structure of $\mathrm{Bu}_{4} \mathrm{~N}^{+}\left[\mathbf{1}^{-}\right] \cdot \mathrm{H}_{2} \mathrm{O}$ (Figure 1) displays two salient features: the occurrence on one single crystallographic site of two equilibrium positions, with unbalanced occupancies of BCP rotators that slightly change from 0.71 and 0.29 at $180 \mathrm{~K}$ to

Received: October 17, 2017

Accepted: January 19, 2018

Published: January 30, 2018 


\section{Scheme 1}<smiles>O=C(O)C#CC1CC2(C#CC(=O)O)CC12</smiles>
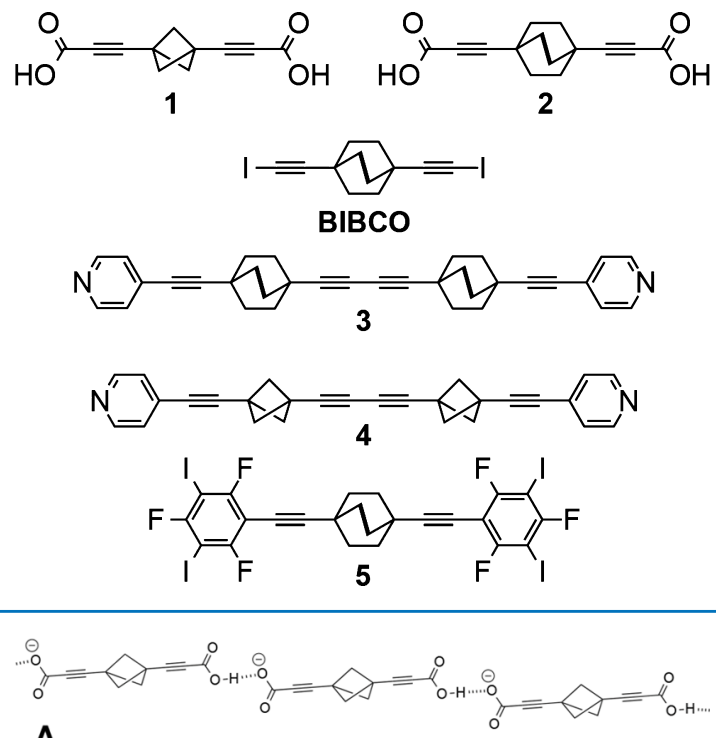

A
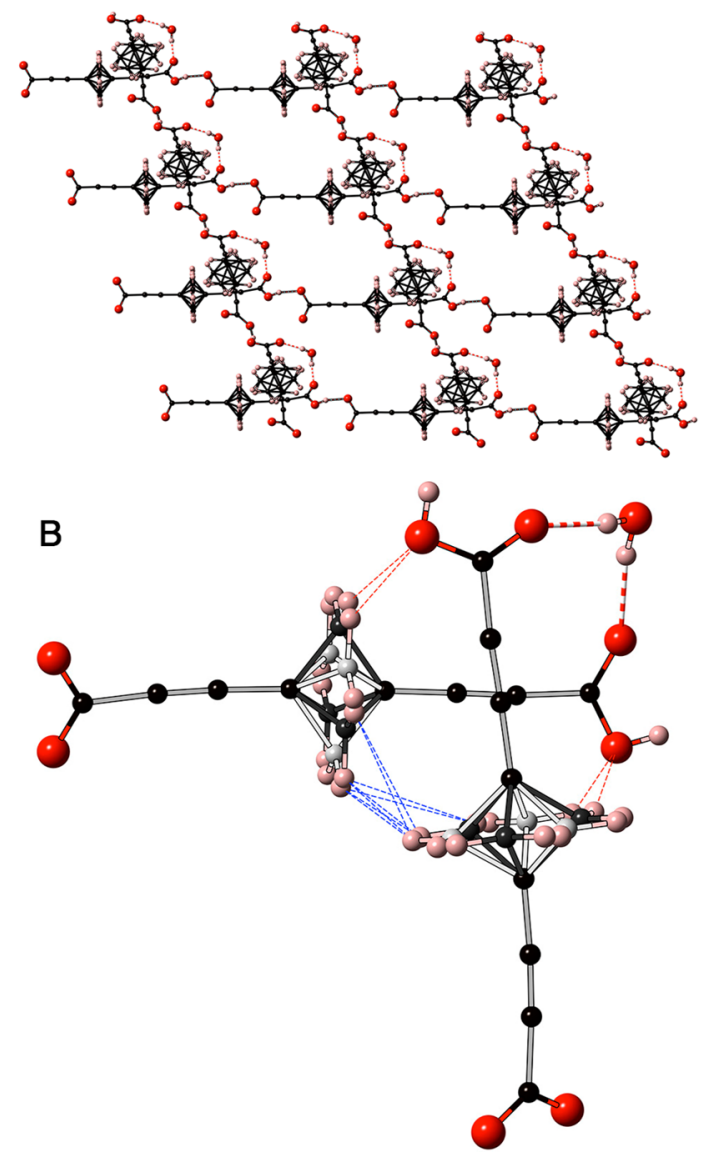

Figure 1. (A) A pair of layers of strings of hydrogen-bonded anions 1 that stack on top of each other along $c$ in $\mathrm{Bu}_{4} \mathrm{~N}^{+}\left[\mathbf{1}^{-}\right] \cdot \mathrm{H}_{2} \mathrm{O}\left(\mathrm{Bu}_{4} \mathrm{~N}^{+}\right.$ omitted for clarity). Hydrogen-bonded water molecules impose the orthogonal configuration of the two layers within a pair; (B) $\mathrm{C}-\mathrm{H} \cdots$ $\mathrm{H}-\mathrm{C}$ (blue dotted lines) and $\mathrm{C}-\mathrm{H} \cdots \mathrm{O}$ (red dotted lines) hydrogen bonds, which determine rotor-rotor and rotor-carboxylate interactions, respectively. Both the majority (0.71) and minority (0.29) occupancy positions (darker and lighter atoms and lines, respectively) of the BCP rotators in dynamic equilibrium in the lattice are represented.
0.83 and 0.17 at $100 \mathrm{~K}$ with no evidence for a phase transition in between, and the presence of pairs of fast rotors despite their rather unusual configuration characterized by orthogonal axles. The pairs of rotors are located far apart in the lattice and do not interact directly.

Two Rotational Barriers; Higher Energy Barrier Unexpectedly Assigned to the Motion of Majority Rotors. Two distinct relaxation processes have been identified (Figure 2) by variable-temperature ${ }^{1} \mathrm{H}$ spin-lattice relaxation

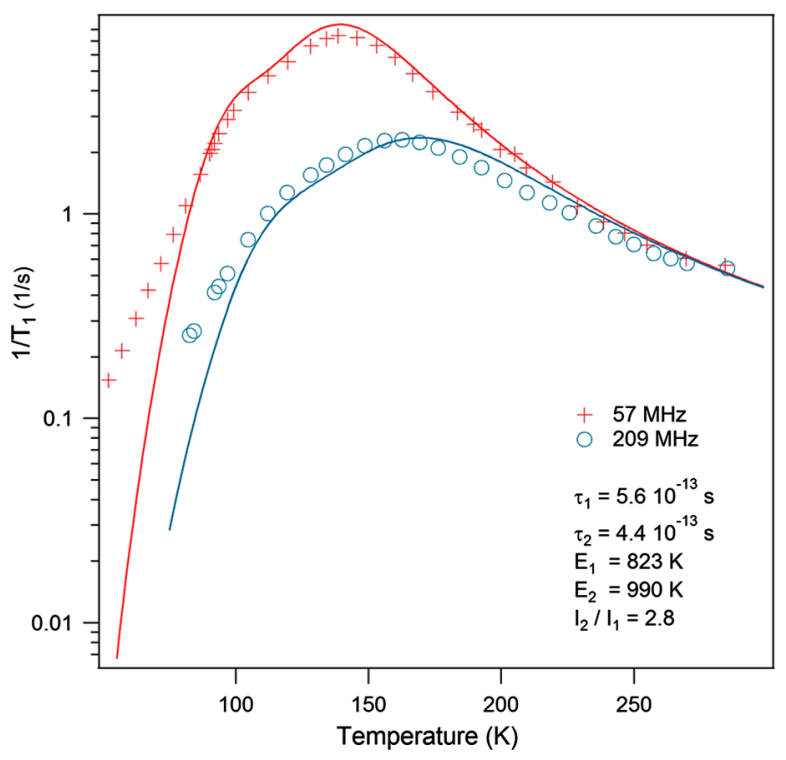

Figure 2. Variable-temperature ${ }^{1} \mathrm{H}$ spin-lattice relaxation time, $T_{1}{ }^{-1}$, at 57 and $209 \mathrm{MHz}$ for a static crystalline sample of $\mathrm{Bu}_{4} \mathrm{~N}^{+}\left[\mathbf{1}^{-}\right] \cdot \mathrm{H}_{2} \mathrm{O}$. The red and blue solid lines represent the fit of the data to the KuboTomita formula, $\tau_{\mathrm{c}}=\tau_{0} \exp \left(E_{\mathrm{a}} / k T\right)$, yielding $E_{\mathrm{a} 1}=823 \mathrm{~K}(1.63 \mathrm{kcal}$ $\left.\mathrm{mol}^{-1}\right)$ and $E_{\mathrm{a} 2}=990 \mathrm{~K}\left(1.97 \mathrm{kcal} \mathrm{mol}^{-1}\right)$, respectively, and the attempt correlation times of $\tau_{1}=5.6 \times 10^{-13} \mathrm{~s}$ and $\tau_{2}=4.4 \times 10^{-13} \mathrm{~s}$, respectively.

time experiments conducted as described previously on a static crystalline powder at two field strengths. ${ }^{1,4,5,8}$ Note that one single relaxation process is typically associated with one single rotor site in the lattice, eventually with several equilibrium positions, for example, as in $5 .{ }^{8}$ The occurrence of two ${ }^{1} \mathrm{H}$ spin-lattice relaxation processes in crystalline rotors has been associated with either one of the two cases: when rotors sit at two different crystallographic sites as in $\mathrm{BIBCO}^{7}$ and $\left[n \mathrm{Bu}_{4} \mathrm{~N}^{+}\right]_{2}[2]\left[2^{-}\right]_{2} ;{ }^{1}$ or as in 3 and 4 , and when a pair of rotators, each sitting at a single site with two equilibrium positions with different occupancies, undergo correlated synchronous motion and occasional asynchronous events, where the difference in energy barriers scales with the strength of their interaction. Note in Figure 2, the perfect fit of $T_{1}{ }^{-1}(T)$ data to the Kubo-Tomita curve for two different rotation barriers, with activation energies $E_{\mathrm{a} 1}=823 \mathrm{~K}\left(1.63 \mathrm{kcal} \mathrm{mol}^{-1}\right)$ and $E_{\mathrm{a} 2}=990 \mathrm{~K}\left(1.97 \mathrm{kcal} \mathrm{mol}^{-1}\right)$; the attempt correlation times $\tau_{1}=5.6 \times 10^{-13} \mathrm{~s}$ and $\tau_{2}=4.4 \times 10^{-13} \mathrm{~s}$, respectively; and an $I_{2} / I_{1}=2.8$ ratio of intensities of the two relaxation peaks. This $I_{2} / I_{1}$ value matches the ratio $(0.71 / 0.29=2.45)$ of the unbalanced occupancies on the single crystallographic site, providing an unambiguous experimental assignment of the higher and lower energy barriers to the motion of rotators in the majority and minority configurations, respectively. $\mathrm{C}-\mathrm{H} \cdots$ $\mathrm{H}-\mathrm{C}$ contacts being shorter in ma-ma pairs (see Figure 3 ), 

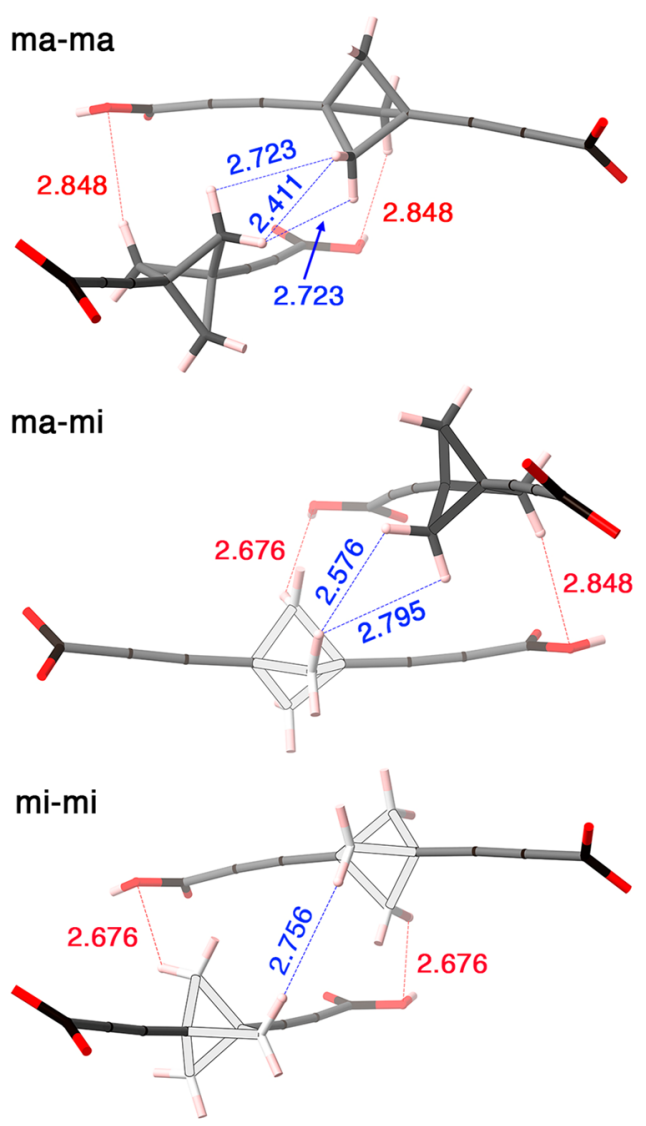

Figure 3. Majority-majority (ma-ma), majority-minority (ma-mi), and minority-minority $(\mathrm{mi}-\mathrm{mi})$ configurations given by the crystal structure (Figure 1).

could be taken as supporting such an assignment. However, this experimental evidence is puzzling, because majority-majority (ma-ma) pairs must be more stable than majority-minority $(\mathrm{ma}-\mathrm{mi})$ pairs, with $\mathrm{mi}-\mathrm{mi}$ pairs being the least stable. Here, on the contrary, the ma-ma pair is associated with shorter $\mathrm{C}-$ $\mathrm{H} \cdots \mathrm{H}-\mathrm{C}$ interactions, and its two BCPs contact each other the most so that it should be the least stable (in addition, note that their $\mathrm{C}-\mathrm{H} \cdots \mathrm{O}$ contacts are longer).

Rotor-Rotor Interaction Energies. To understand the origin of these two barriers and solve this puzzling experimental assignment, we need calculations of rotor-rotor interaction energies. As in previous studies, ${ }^{1,4,5,8}$ density functional theory calculations were carried out (Supporting Information) to estimate the rotational barriers searching for the lowest energy paths by means of partial geometry optimizations, starting from the ma-ma and ma-mi configurations given by the crystal structure (Figure 3). The terminal groups $\mathrm{C} \equiv \mathrm{C}-\mathrm{CO}_{2}^{-}$and $\mathrm{C} \equiv \mathrm{C}-\mathrm{CO}_{2} \mathrm{H}$ were maintained fixed at their crystallographic positions; geometry optimizations were conducted in two ways, as exemplified in Figure 4. We next analyzed the energy profiles (Figure 4) computed for the different rotational motions of the majority and minority rotators in the pairs.

When the motion of the atoms of the three blades of each rotator was optimized with only one constraint (either $\theta_{1}$ or $\theta_{2}$ is fixed at different values), the curves denoted ma-ma II, mami II ( $\theta$ of the ma rotor is the constraint), and ma-mi III ( $\theta$ of the mi rotor is the constraint) exhibit a very irregular profile. This was unexpected and contrasted sharply with the results of our previous calculations for the pairs of rotators with parallel
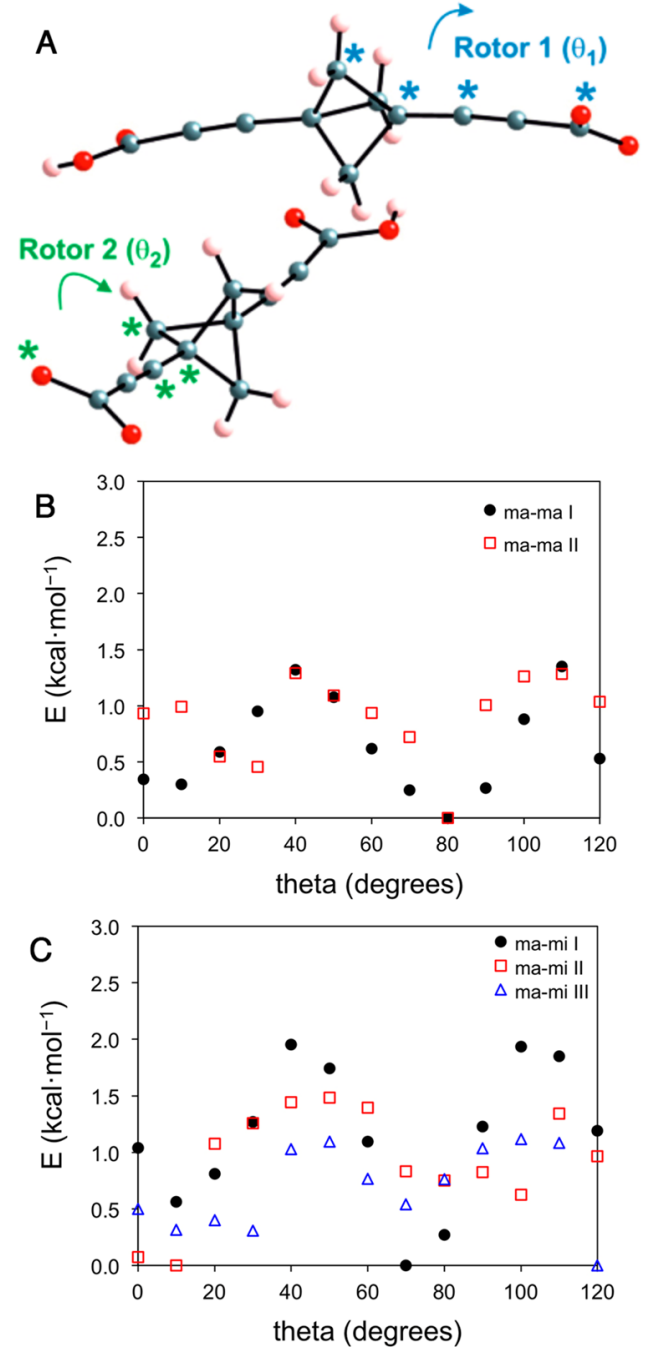

Figure 4. (A) Two protocols for the geometry optimization: Either (i) $\theta_{1}$ is given a set value and the geometry of the three blades of each rotor is optimized or (ii) $\theta_{1}$ and $\theta_{2}$ are given set values to impose a motion of both rotors (see text), and the geometry is optimized. The computed energy profiles for the ma-ma (B) and ma-mi (C) pairs of $\mathrm{BCP}$ rotators (see the text for a detailed explanation).

axles, where the rotational profiles typically exhibit the $60^{\circ}$ periodicity expected for an ideal case. Only ma-ma I and mami I, calculated with the constraint $\theta_{1}=\theta_{2}$, show some degree of periodicity. Also, in contrast with the cases of the parallel rotators studied earlier, it was not possible to understand the shape of these profiles by considering only the evolution of the $\mathrm{C}-\mathrm{H} \cdots \mathrm{H}-\mathrm{C}$ interactions between rotators, suggesting that they are not the only contributors to rotational barriers when the rotator axles are orthogonal. Instead, interactions between the hydrogen atoms of the rotator blades and the oxygen atoms of the carboxylic groups may become relevant and should also be taken into account. However, even when the evolution of both $\mathrm{C}-\mathrm{H} \cdots \mathrm{H}-\mathrm{C}$ and $\mathrm{C}-\mathrm{H} \cdots \mathrm{O}$ distances along the rotational motion associated with hydrogen atoms of the rotators were accounted for, it was not possible to rationalize the calculated profiles. We checked that the $\mathrm{C}-\mathrm{H} \cdots \mathrm{H}-\mathrm{C}$ interactions between rotator blades and $\mathrm{Bu}_{4} \mathrm{~N}^{+}$are long and similar and that the $\mathrm{H}_{2} \mathrm{O}$ linker molecules do not make short contacts with the hydrogen atoms of the rotators. 
Directionality of the $\mathrm{C}-\mathrm{H} \cdots \mathrm{O}$ Interactions in a Pair Is the Key to the Mechanism of Motion. To make progress, we must return to the crystal structure and consider the differences between the ma-ma, ma-mi, and $\mathrm{mi}-\mathrm{mi}$ configurations. Consideration of neither the $\mathrm{C}-\mathrm{H} \cdots \mathrm{H}-\mathrm{C}$ nor the $\mathrm{C}-\mathrm{H} \cdots \mathrm{O}$ contacts provides an understanding of the stability order. Taking a closer look at the directionality of the $\mathrm{C}-\mathrm{H} \cdots \mathrm{O}$ interactions in a pair (red-dotted lines in Figure $1 B$ ), we found that the lone pairs of the oxygen atoms are not far from a tetrahedral local geometry so that for a given $\mathrm{H} \cdots \mathrm{O}$ distance, the interaction will be stronger when $\mathrm{C}-\mathrm{H}$ points toward one of these lone pairs, that is, when $\mathrm{C}-\mathrm{H} \cdots \mathrm{O}$ and $\mathrm{H}-$ $\mathrm{O} \cdots \mathrm{H}$ angles are as close as possible to $180^{\circ}$ and $109^{\circ}$, respectively. With this in mind, we then realized that although in the ma-ma configuration the $\mathrm{H} \cdots \mathrm{O}$ distance is somewhat longer, its orientation is considerably better $(\mathrm{H}-\mathrm{O} \cdots \mathrm{H}=$ $\left.106.5^{\circ} ; \mathrm{C}-\mathrm{H} \cdots \mathrm{O}=160.6^{\circ}\right)$ than that in the $\mathrm{mi}-\mathrm{mi}$ configuration $\left(\mathrm{H}-\mathrm{O} \cdots \mathrm{H}=116.9^{\circ} ; \mathrm{C}-\mathrm{H} \cdots \mathrm{O}=135.7^{\circ}\right)$. We thus conclude that the directionality effect of the $\mathrm{C}-\mathrm{H} \cdots \mathrm{O}$ interaction overrides the effect of the slightly longer $\mathrm{H} \cdots \mathrm{O}$ distance and stabilizes preferentially the majority configuration. Ultimately, a trade-off between $\mathrm{C}-\mathrm{H} \cdots \mathrm{H}-\mathrm{C}$ and $\mathrm{C}-\mathrm{H} \cdots \mathrm{O}$ interactions leads to an unbalanced 71:29 occupancy between the majority and minority configurations in dynamic equilibrium in the lattice. In fact, our calculations led to a very slight $0.1 \mathrm{kcal} \mathrm{mol}^{-1}$ preference for the ma-ma configuration. This value should be taken with a grain of salt because it is a result of competing weak effects, yet it would be consistent, with a slight underestimation of the $\mathrm{H} \cdots \mathrm{O}$ interaction in our calculation.

Taking into account both the distance and orientation of $\mathrm{C}-$ $\mathrm{H} \cdots \mathrm{O}$ interactions as well as $\mathrm{C}-\mathrm{H} \cdots \mathrm{H}-\mathrm{C}$ contacts, the detailed structural evolution of the pairs of rotors along the rotational profiles can be understood. With no structural restriction imposed in the calculations, one $\mathrm{C}-\mathrm{H} \cdots \mathrm{O}$ interaction is essentially maintained unchanged (see, for instance, the structural reorganization along the rotational motion for mama II in the Supporting Information Figure S1), whereas the other $\mathrm{C}-\mathrm{H} \cdots \mathrm{O}$ interaction and $\mathrm{C}-\mathrm{H} \cdots \mathrm{H}-\mathrm{C}$ interactions evolve during the rotation. In other words, the blades of one rotator barely move whereas those of the other rotate, severely disrupting its own $\mathrm{C}-\mathrm{H} \cdots \mathrm{O}$ interaction. A majority rotor is maintained practically unchanged in the calculated paths for ma-ma II and ma-mi III, but the minority rotor is blocked in ma-mi II. In contrast, neither of the two rotors is blocked along the paths for ma-ma I and ma-mi I. For ma-ma pairs, the two rotational motions are almost identical $(1.30-1.35 \mathrm{kcal}$ $\left.\mathrm{mol}^{-1}\right)$. In contrast, for ma-mi pairs, the asymmetric motion is clearly advantageous; when the mi rotor is blocked (ma-mi II), the activation barrier $\left(1.45 \mathrm{kcal} \mathrm{mol}^{-1}\right)$ is not far from the previous ones, but when the ma rotor is blocked (ma-mi III), the barrier is definitely lower $\left(1.08 \mathrm{kcal} \mathrm{mol}^{-1}\right)$.

In a ma-mi Pair, It Is the Minority Rotor That Is Moving Faster. To summarize, we can now understand the mechanism of motion as well as the experimental assignment based on the ratio of intensities of the two $T_{1}{ }^{-1}$ peaks. For asymmetric motions in a ma-mi pair, it is the minority rotor that is moving faster because its $\mathrm{C}-\mathrm{H} \cdots \mathrm{O}$ interaction is initially weaker on account of its misalignment with the ma oxygen lone pair, that is, its barrier is slightly smaller. In contrast, the barrier for a majority rotor either in ma-ma or ma-mi pairs is slightly larger because its $\mathrm{C}-\mathrm{H} \cdots \mathrm{O}$ interaction is initially somewhat stronger. In addition, when both rotors move in a pair, the barrier for the ma-ma pair is again of the same order as those for asymmetric motions of the ma rotor, whereas for the mami pair, it is larger $\left(1.95 \mathrm{kcal} \mathrm{mol}^{-1}\right)$ by a sizeable margin. This explains why the ratio of intensities of the two $T_{1}^{-1}$ maxima associated with the experimental barriers is almost identical to the ratio of occupancies of the two rotator equilibrium positions in the crystal structure. In short, the perpendicular orientation of the two rotors in a pair brings about a radically different rotational motion compared with all previously studied BCP- and BCO-based solids with pairs of parallel rotators.

\section{ASSOCIATED CONTENT}

\section{Supporting Information}

The Supporting Information is available free of charge on the ACS Publications website at DOI: 10.1021/acsomega.7b01580.

Synthesis, crystal structure, VT ${ }^{1} \mathrm{H}$ spin-lattice relaxation time experiments, and computational details (PDF)

Crystallographic data (CCDC-1580416) (CIF) Crystallographic data (CCDC-1812873) (CIF)

\section{AUTHOR INFORMATION}

\section{Corresponding Authors}

*E-mail: canadell@icmab.es (E.C.).

*E-mail: pawel.wzietek@u-psud.fr (P.W.).

*E-mail: michlj@colorado.edu (J.M.).

*E-mail: patrick.batail@univ-angers.fr (P.B.).

ORCID

Antonio Rodríguez-Fortea: 0000-0001-5884-5629

Enric Canadell: 0000-0002-4663-5226

Patrick Batail: 0000-0001-7125-5009

Notes

The authors declare no competing financial interest.

\section{ACKNOWLEDGMENTS}

Work in Bellaterra and Tarragona was supported by the Spanish Ministerio de Economia y Competitividad (projects FIS2015-64886-C5-4-P and CTQ2017-87269-P) and Generalitat de Catalunya (2014GR301 and 2014GR199). E.C. acknowledges the support of the Spanish MINECO through the Severo Ochoa Centers of Excellence Program under grant SEV-2015-0496. J.K. and J.M. gratefully acknowledge financial support from the European Research Council under the European Community's Framework Programme (FP7/20072013) ERC grant agreement no. 227756 and the Institute of Organic Chemistry and Biochemistry, Academy of Sciences of the Czech Republic (RVO: 61388963). This material is based upon work supported by the National Science Foundation under grant no. CHE-1566435. Work at Orsay was supported by the CNRS. Work at Angers was supported by the CNRS and the Région des Pays de la Loire grant MOVAMOL. Joint work at Angers, Orsay, and Prague was supported by the Ministère de l'Europe et des Affaires Etrangères under the grant PHC Barrande no. 864563J.

\section{REFERENCES}

(1) Lemouchi, C.; Mézière, C.; Zorina, L.; Simonov, S.; RodríguezFortea, A.; Canadell, E.; Wzietek, P.; Auban-Senzier, P.; Pasquier, C.; Giamarchi, T.; Garcia-Garibay, M. A.; Batail, P. Design and evaluation of a crystalline hybrid of molecular conductors and molecular rotors. $J$. Am. Chem. Soc. 2012, 134, 7880-7891.

(2) (a) Kaleta, J.; Nečas, M.; Mazal, C. 1,3-Diethynylbicyclo[1.1.1]pentane, a useful molecular building block. Eur. J. Org. Chem. 2012, 
4783-4796. (b) Kaleta, J.; Michl, J.; Mazal, C. T-shaped molecular building blocks by combined bridgehead and bridge substitution on bicyclo[1.1.1] pentanes. J. Org. Chem. 2010, 75, 2350-2356. (c) Kaleta, J.; Janoušek, Z.; Nečas, M.; Mazal, C. Molecular rods combining ocarborane and bicyclo[1.1.1]pentane cages: an insertion of the triple bond located next to a highly strained cage. Organometallics 2015, 34, 967-972. (d) Cipolloni, M.; Kaleta, J.; Mašát, M.; Dron, P. I.; Shen, Y.; Zhao, K.; Rogers, C. T.; Shoemaker, R. K.; Michl, J. Time-resolved fluorescence anisotropy of bicyclo[1.1.1]pentane/tolane-based molecular rods included in tris(o-phenylenedioxy)cyclotriphosphazene (TPP). J. Phys. Chem. C 2015, 119, 8805-8820.

(3) (a) Iwamura, H.; Mislow, K. Stereochemical consequences of dynamic gearing. Acc. Chem. Res. 1988, 21, 175-182. (b) Nakamura, M.; Kishimoto, K.; Kobori, Y.; Abe, T.; Yoza, K.; Kobayashi, K. Selfassembled molecular gear: a 4:1 complex of $\mathrm{Rh}(\mathrm{III}) \mathrm{Cl}$ tetraarylporphyrin and tetra(p-pyridyl)cavitand. J. Am. Chem. Soc. 2016, 138, 12564-12577. (c) Jiang, X.; O’Brien, Z. J.; Yang, S.; Lai, L. H.; Buenaflor, J.; Tan, C.; Khan, S.; Houk, K. N.; Garcia-Garibay, M. A. Crystal fluidity reflected by fast rotational motion at the core, branches, and Peripheral aromatic groups of a dendrimeric molecular rotor. J. Am. Chem. Soc. 2016, 138, 4650-4656. (d) Sanada, K.; Ube, H.; Shionoya, M. Rotational control of a dirhodium-centered supramolecular four-gear system by ligand exchange. J. Am. Chem. Soc. 2016, 138, 2945-2948. (e) Frantz, D. K.; Linden, A.; Baldridge, K. K.; Siegel, J. S. Molecular spur gears comprising triptycene rotators and bibenzimidazole-based stators. J. Am. Chem. Soc. 2012, 134, 15281535 .

(4) (a) Lemouchi, C.; Iliopoulos, K.; Zorina, L.; Simonov, S.; Wzietek, P.; Cauchy, T.; Rodríguez-Fortea, A.; Canadell, E.; Kaleta, J.; Michl, J.; Gindre, D.; Chrysos, M.; Batail, P. Crystalline Arrays of Pairs of Molecular Rotors: Correlated Motion, Rotational Barriers, and Space Inversion-symmetry Breaking due to Conformational Mutations. J. Am. Chem. Soc. 2013, 135, 9366-9376. (b) Bastien, G.; Lemouchi, C.; Allain, M.; Wzietek, P.; Rodríguez-Fortea, A.; Canadell, E.; Iliopoulos, K.; Gindre, D.; Chrysos, M.; Batail, P. Changing gears to neutral in a polymorph of one-dimensional arrays of cogwheel-like pairs of molecular rotor. CrystEngComm 2014, 16, 1241-1244.

(5) Kaleta, J.; Michl, J.; Mézière, C.; Simonov, S.; Zorina, L.; Wzietek, P.; Rodríguez-Fortea, A.; Canadell, E.; Batail, P. Gearing motion in cogwheels pairs of molecular rotors: weak-coupling limit. CrystEngComm 2015, 17, 7829-7834.

(6) Understanding the mechanism of motion is key to control molecular machines, see: (a) Domingos, S. R.; Cnossen, A.; Buma, W. J.; Browne, W. R.; Feringa, B. L.; Schnell, M. Cold snapshot of a molecular rotary motor captured by high-resolution rotational spectroscopy. Angew. Chem., Int. Ed. 2017, 56, 11209-11212. (b) Steigleder, E.; Shima, T.; Lang, G. M.; Ehnbom, A.; Hampel, F.; Gladysz, J. A. Partially shielded $\mathrm{Fe}(\mathrm{CO})_{3}$ rotors: syntheses, structures, and dynamic properties of complexes with doubly trans spanning diphosphines, trans-[ $\left.\mathrm{Fe}(\mathrm{CO})_{3}\left(\mathrm{PhP}\left(\left(\mathrm{CH}_{2}\right) \mathrm{n}\right)_{2}\right] \mathrm{PPh}\right)$. Organometallics 2017, 36, 2891-2901. (c) Faulkner, A.; van Leeuwen, T.; Feringa, B. L.; Wezenberg, S. J. Allosteric regulation of the rotational speed in a light-driven molecular motor. J. Am. Chem. Soc. 2016, 138, 1359713603. (d) Abendroth, J. M.; Bushuyev, O. S.; Weiss, P. S.; Barrett, C. $\mathrm{J}$. Controlling motion at the nanoscale: rise of the molecular machines. ACS Nano 2015, 9, 7746-7768. (e) Erbas-Cakmak, S.; Leigh, D. A.; McTernan, C. T.; Nussbaumer, A. L. Artificial molecular machines. Chem. Rev. 2015, 115, 10081-10206. (f) Vogelsberg, C. S.; GarciaGaribay, M. A. Crystalline molecular machines: function, phase order, dimensionality, and composition. Chem. Soc. Rev. 2012, 41, 18921910.

(7) Lemouchi, C.; Vogelsberg, C. S.; Zorina, L.; Simonov, S.; Batail, P.; Brown, S.; Garcia-Garibay, M. A. Ultra-fast rotors for molecular machines and functional materials via halogen bonding: crystals of 1,4bis(iodoethynyl)bicyclo[2.2.2] octane with distinct gigahertz rotation at two sites. J. Am. Chem. Soc. 2011, 133, 6371-6379.

(8) Lemouchi, C.; Yamamoto, H. M.; Kato, R.; Simonov, S.; Zorina, L.; Rodríguez-Fortea, A.; Canadell, E.; Wzietek, P.; Iliopoulos, K.; Gindre, D.; Chrysos, M.; Batail, P. Reversible control of crystalline rotors by squeezing their hydrogen bond cloud across a halogen bondmediated phase transition. Cryst. Growth Des. 2014, 14, 3375-3383. 